\title{
Molluscicidal and parasiticidal activities of Eryngium triquetrum essential oil on Schistosoma mansoni and its intermediate snail host Biomphalaria glabrata, a double impact
}

Ronaldo de Carvalho Augusto ${ }^{1,2 \dagger}$, Nadjiya Merad ${ }^{3 \dagger}$, Anne Rognon ${ }^{1,2}$, Benjamin Gourball ${ }^{1,2}$, Cédric Bertrand ${ }^{4,5,6}$, Nassim Djabou $3^{3^{*}}$ and David Duval ${ }^{1,2^{*}}$

\begin{abstract}
Background: Freshwater snails are the intermediate hosts of a large variety of trematode flukes such as Schistosoma mansoni responsible for one of the most important parasitic diseases caused by helminths, affecting 67 million people worldwide. Recently, the WHO Global Vector Control Response 2017-2030 (GVCR) programme reinforced its message for safer molluscicides as part of required strategies to strengthen vector control worldwide. Here, we present the essential oil from Eryngium triquetrum as a powerful product with molluscicide and parasiticide effect against $S$. mansoni and the snail intermediate host Biomphalaria glabrata.
\end{abstract}

Methods: In the present study, we describe using several experimental approaches, the chemical composition of $E$. triquetrum essential oil extract and its biological effects against the snail B. glabrata and its parasite S. mansoni. Vector and the free-swimming larval stages of the parasite were exposed to different oil concentrations to determine the lethal concentration required to produce a mortality of $50 \%\left(\mathrm{LC}_{50}\right)$ and $90 \%\left(\mathrm{LC}_{90}\right)$. In addition, toxic activity of this essential oil was analyzed against embryos of B. glabrata snails by monitoring egg hatching and snail development. Also, short-time exposure to sublethal molluscicide concentrations on $\mathrm{S}$. mansoni miracidia was performed to test a potential effect on parasite infectivity on snails. Mortality of miracidia and cercariae of S. mansoni is complete for 5, 1 and 0.5 ppm of oil extract after 1 and $4 \mathrm{~h}$ exposure.

Results: The major chemical component found in E. triquetrum oil determined by GC-FID and GC/MS analyses is an aliphatic polyacetylene molecule, the falcarinol with $86.9-93.1 \%$ of the total composition. The $L_{50}$ and $L C_{90}$ values for uninfected snails were 0.61 and $1.02 \mathrm{ppm}$ respectively for $24 \mathrm{~h}$ exposure. At $0.5 \mathrm{ppm}$, the essential oil was two times more toxic to parasitized snails with a mortality rate of $88.8 \pm 4.8 \%$. Moderate embryonic lethal effects were observed

\footnotetext{
*Correspondence: nassim.djabou@mail.univ-tlemcen.dz; david.duval@univ-

perp.fr

${ }^{\dagger}$ Ronaldo de Carvalho Augusto and Nadjiya Merad contributed equally to this work

1 University Perpignan Via Domitia, IHPE, UMR 5244, CNRS, IFREMER, Perpignan, France

${ }^{3}$ Faculté des Sciences, Département de Chimie, Université de Tlemcen, Laboratoire COSNA, Tlemcen, Algeria

Full list of author information is available at the end of the article
}

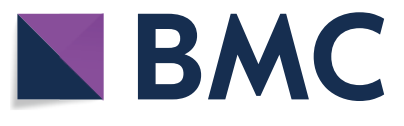
adaptation, distribution and reproduction in any medium or format, as long as you give appropriate credit to the original author(s) and the source, provide a link to the Creative Commons licence, and indicate if changes were made. The images or other third party material in this article are included in the article's Creative Commons licence, unless indicated otherwise in a credit line to the material. If material is not included in the article's Creative Commons licence and your intended use is not permitted by statutory regulation or exceeds the permitted use, you will need to obtain permission directly from the copyright holder. To view a copy of this licence, visit http://creativecommons.org/licenses/by/4.0/. The Creative Commons Public Domain Dedication waiver (http://creativecommons.org/publicdomain/zero/1.0/) applies to the data made available in this article, unless otherwise stated in a credit line to the data. 
at the concentration of $1 \mathrm{ppm}$. Severe surface damage in miracidia was observed with a general loss of cilia that probably cause their immobility. Miracidia exposed $30 \mathrm{~min}$ to low concentration of plant extract (0.1 ppm) were less infective with 3.3\% of prevalence compare to untreated with a prevalence of $44 \%$.

Conclusions: Essential oil extracted from E. triquetrum and falcarinol must be considered as a promising product for the development of new interventions for schistosomiasis control and could proceed to be tested on Phase II according to the $\mathrm{WHO}$ requirements.

Keywords: Biomphalaria glabrata, Eryngium triquetrum, Molluscicide, Oil, Parasiticide, Schistosoma mansoni

\section{Background}

Water-borne infectious diseases, mainly those involving digenetic parasites, are mediated by both ecological and socioeconomic processes, and constitute an important public health problem in developing countries [1]. Schistosomiasis is one of the most common parasitic diseases worldwide [2]. It is particularly prevalent among people living in rural or deprived urban or peri-urban settings with limited access to clean water and with inadequate sanitation provision [3, 4]. Digenetic schistosomes have complex life-cycles entailing both mammalian hosts, including humans, and freshwater snail hosts. During their development, schistosomes have to deal with organic and inorganic compounds once in freshwater and then must face a multitude of molecules once inside both hosts [5]. For the control of schistosomiasis, the World Health Organization (WHO) recommends the mass administration of the chemotherapeutic praziquantel (PZQ), but also health education, technical cooperation between health institutions and research to verify the elimination of infection, and control of snail populations $[2,6]$.

The complexity of the parasite life-cycle gives rise to a complex list of requirements to obtain a successful control programme. Traditional models based exclusively on the use of schistosomicidal drugs have proven to significantly reduce morbidity in infected individuals, but the prevalence in the field remains high after decades of treatment. Indeed, continuous mass drug administration (MDA) campaigns in Africa and Brazil with PZQ, were not successful to eradicate the disease and a high prevalence and territorial expansion of infection areas are still detected worldwide [7]. Besides this, control strategies based only on one trial are struggling and deserve special attention since cases of rapid adaptation of the parasites to various treatment or specific environmental cues have been documented [5, 7-10]. To integrate MDA approaches, the WHO recommends the use of the synthetic molluscicide niclosamide (Bayluscide ${ }^{\circledR}$ ) as one of the strategies to fight schistosomiasis in the field [2]. However, niclosamide has high a production value and can induce several secondary effects, such as bioaccumulation and high toxicity in non-target animals [11]. Also, snails resistant to niclosamide appeared recently and thus finding new molluscicides becomes necessary [12]. It is currently expected that we will see the development of a new class of safer molluscicides, which should be less harmful to the non-target organisms and, if possible, will be more selective to snails infected with schistosomes [13]. Increasing efforts have been made to focus on identifying and characterizing plant-derived molluscicides as safer alternatives [14-19].

In this study, we have focused on an essential oil extracted from Eryngium triquetrum. This Apiaceae is an endemic species of northern Africa, distributed in all parts of Algeria; the green perennial plant becomes a bluish-purplish color when ripe. This species grows particularly well in rocky pastures. It was considered as a ruderal species, which the local people call 'choukzerk' [20]. No traditional use for this thorny plant has been reported by the Algerian population. However, species of the genus Eryngium are used as a folk remedy for the treatment of various inflammatory disorders, and as an emetic infusion, antidote for poisons, hypoglycemic, antitussive and diuretic agents [21-24]. Species of Eryngium have been subjects of many phytochemical studies. For example, hexanic extract of $E$. campestre showed anti-trypanosomal and leishmanial activities [23]. Eryngium caeruleum extract displayed antimicrobial activities [25]. The essential oil of E. triquetrum for which the chemical composition was reported exhibits a moderate antibacterial action against Gram-positive and Gram-negative bacteria [23].

In order to further analyze the biological activity of E. triquetrum, we characterize and investigate the toxic effects of its essential oil against $S$. mansoni free-swimming stages (miracidia and cercariae) and on adults and embryos of the snail B. glabrata. Our results suggest that this biological compound could be used as a biological control agent against $B$. glabrata snails and its parasite $S$. mansoni. 


\section{Methods}

Plant material and essential oil extraction

The fresh stems of E. triquetrum were harvested from June 2017, from three localities of northwest Algeria (Samples ET01-ET03) as described in the Table 1.

The essential oil extractions were performed using a Clevenger-type apparatus according to the method recommended in the European Pharmacopoeia [26]. A sample of 400-500 $\mathrm{g}$ of the fresh plant was subjected to hydrodistillation.

\section{Compound identification}

The identification of individual components was based on: (i) the comparison of the retention indices (RIs) determined on nonpolar columns with those of authentic compounds or literature data [27]; (ii) computer matching of the mass spectra with commercial mass-spectral libraries; and (iii) the comparison of the mass spectra with those listed in our in-house library built of mass spectra of authentic compounds or literature data [28].

\section{Compound quantification}

Quantification of the oil components was performed using the methodology reported by Rubiolo et al. [29] and adapted in our laboratory [30]. Briefly, the compound quantification was carried out using peak normalization, including FID response factors (RFs) relative to tridecane $(0.7 \mathrm{~g} / 100 \mathrm{~g})$ used as internal standard, and expressed as normalized contents (\% abundances).

\section{Gas chromatography}

Essential oil samples were analyzed with Thermo Scientific Focus GC with Detector Flame Ionization (FID) using an SPB-1 column fused silica capillary $(30 \mathrm{~m} \times$ $0.25 \mathrm{~mm} \times 0.25 \mu \mathrm{m}$ ) with helium as the carrier gas (flow rate $1.0 \mathrm{ml} / \mathrm{min}$ ) and an injection volume of $1 \mu \mathrm{l}$ (solution in cyclohexane); the initial pressure was $1.0 \mathrm{~Pa}$. The oven temperature was programmed as follows: $60{ }^{\circ} \mathrm{C}$ for $3 \mathrm{~min}, 60-240{ }^{\circ} \mathrm{C}\left(3^{\circ} \mathrm{C} \mathrm{min}^{-1}\right), 240-300{ }^{\circ} \mathrm{C}\left(10^{\circ} \mathrm{C} \mathrm{min}^{-1}\right)$ and $300{ }^{\circ} \mathrm{C}$ for $10 \mathrm{~min}$. The injector temperature was 235 ${ }^{\circ} \mathrm{C}$, the detector temperature was $300{ }^{\circ} \mathrm{C}$ with injection in the 'splitless' mode. The analyses lasted $80 \mathrm{~min}$. Samples were analyzed in triplicate. The retention indices (RIs) of the compounds were determined related to the retention times (RT) of a series of n-alkanes (C7-C40) using the Van den Dool-Kratz equation.

\section{Gas chromatography-mass spectrometry}

Thermo Scientific DSQ ${ }^{\mathrm{TM}}$ II gas chromatography coupled with a mass spectrometry detector, was performed with the same conditions that were previously described in Gas Chromatography. MS data were collected and processed on an $\mathrm{Xcalibur}^{\mathrm{TM}}$ version 1.4.1. For mass spectrometry conditions, the electron ionization was 70 $\mathrm{eV}$.

\section{Experimentals animals}

Biomphalaria glabrata originating from Recife, Brazil (BgBRE2), was used for this study. These snails were maintained in rearing chambers at $26{ }^{\circ} \mathrm{C}, 12: 12 \mathrm{~h}$ light:dark photoperiod and fed ad libitum with fresh lettuce. A Puerto Rican strain (NMRI) of S. mansoni was used in this study to determine the effects of molluscicide on the susceptibility of infected snails and host-parasite compatibility.

\section{Material collection and extraction of essential oil from Eryngium triquetrum}

Control experiments were performed with $1 \%$ dimethyl sulphoxide (DMSO) diluted with distilled and sterile water. Each essential oil (ET01, ET02 and ET03) was dissolved in DMSO to obtain different solutions in the following concentrations: $1 \mathrm{~g} / \mathrm{ml}, 200 \mathrm{mg} / \mathrm{ml}, 40 \mathrm{mg} / \mathrm{ml}, 10$ $\mathrm{mg} / \mathrm{ml}, 2 \mathrm{mg} / \mathrm{l}, 0.2 \mathrm{mg} / \mathrm{ml}$ and $0.02 \mathrm{mg} / \mathrm{ml}$. Then, each stock solution was diluted in natural mineral water to prepare the different test solutions.

\section{Molluscicidal bioassays}

Biological assays against the snail B. glabrata were carried out following Phase I of stages of evaluation of molluscicides methods recommended by the WHO [31]. Briefly, 12 snails with shell diameters of 6-8 mm were individually exposed to different concentrations of essential oil or DMSO used as control into 12-well tissue culture plate (about $5.5 \mathrm{ml}$ ). All snails were immersed during $24 \mathrm{~h}$ and then washed and transferred to acrylic tanks filled with 5 liters with well water. Snails were fed with fresh lettuce ad labitum during the observation period (48 h). Each snail was observed under binocular microscope to appreciate the heart movements. No difference in mortality was found between the different recovery periods, 24 or $48 \mathrm{~h}$ respectively. To determine the lethal concentration $\mathrm{LC}_{50}$, Probit analysis was used from the three independent experiments performed with the different extract of essential oil.

Table 1 Sample location of Eryngium triquetrum essential oil from three distinct geographical localities in Algeria

\begin{tabular}{llll}
\hline & ET01 & ET02 & ET03 \\
\hline Locality & Bouhanak & Ain fezza & Mefrouch \\
Latitude & $35^{\circ} 08^{\prime} 16.22^{\prime \prime} \mathrm{N}$ & $34^{\circ} 52^{\prime} 37.96^{\prime \prime} \mathrm{N}$ & $34^{\circ} 50^{\prime} 59.19^{\prime \prime} \mathrm{N}$ \\
Longitude & $1^{\circ} 25^{\prime} 20.67^{\prime \prime} \mathrm{W}$ & $1^{\circ} 14^{\prime} 07.62^{\prime \prime} \mathrm{W}$ & $1^{\circ} 17^{\prime} 46.06^{\prime \prime} \mathrm{W}$ \\
Altitude $(\mathrm{m})$ & 313 & 853 & 1108 \\
\hline
\end{tabular}


Concerning assays on infected snails, each snail was exposed to 5 miracidia from the NMRI strain of $S$. mansoni. The procedures of miracidial recovery and snail infection were as conducted and described by Mone et al. [32]. Snail infection status was assessed by direct observation of daughter sporoscyts through the shell of exposed snails. After 15 days of exposure to parasites, 20-30 infected snails were submitted to different doses of essential oil from E. triquetrum to compare their toxic sensitivity with non-infected snails. This experiment was repeated three times at different times by different experimenters.

\section{Miracidiacidal and cercariacidal properties of essential oil from Eryngium triquetrum}

Miracidia from NMRI strain were hatched from eggs recovered from hamster livers after 50 days post-infection. Eggs were filtered and washed to obtain miracidia which were collected under illumination. About 300 freshly hatched miracidia were used to test the toxicity of the essential oil from E. triquetrum. Swimming behavior and mortality were investigated after 1 and $4 \mathrm{~h}$ of treatments. All observations were done using Zeiss LSM microscope and stereoscopic microscope.

Infected B. glabrata (BgBre2) were exposed to artificial light to induce cercarial emission. About 100 cercariae were collected and exposed to different concentrations of essential oil in duplicates. Immobile cercariae were considered as dead.

\section{Impact of the active component derived from Eryngium triquetrum on S. mansoni-B. glabrata compatibility}

The freshly hatched miracidia were recovered and exposed to 0.5 or $0.1 \mathrm{ppm}$ of essential oil for $30 \mathrm{~min}$. Then, each miracidium was collected individually to be placed with a single snail in $5 \mathrm{ml}$ of dechlorinated water. For each condition, 42 snails were exposed individually to 1 miracidium which was treated with essential oil or left untreated. Prevalence was determined for each condition 40 days post-infection as described above.

\section{Toxicity of Eryngium triquetrum essential oil on B. glabrata embryos}

Toxicity of the essential oil was evaluated against egg masses exposed during $24 \mathrm{~h}$ at three concentrations (1, 0.5 and $0.1 \mathrm{ppm})$. Embryonic development of the snails in egg masses was followed for 20 days under a binocular microscope after egg hatching. Polystyrene sheets served as substrate for oviposition. Egg masses were collected gently to avoid damaging them and maintained in Petri dishes with Volvic water. Twenty-four hours after exposition, the egg masses were washed with Volvic water and placed in a cell culture plate (Sarstedt). No selection of egg masses has been done according to the stage of development. The presence of all embryonic stages (blastula, gastrula, trochophore, veliger and hippo stage) has been checked. This toxicity test was carried out twice on more than 25 egg masses per condition.

\section{Statistical analysis}

In all biological assays, at least three independent experiments were conducted at different times. The results were expressed as the mean \pm standard deviation and subjected to the Fischer's exact test. The lethal dose concentrations $\left(\mathrm{LC}_{90}\right.$ and $\mathrm{LC}_{50}$ ) for each essential oil were calculated using a program employing probit analysis [33].

\section{Results}

\section{Chemical characterization of the essential oil extracted} from Eryngium triquetrum

The sampling of plant material in the three locations of northwest Algeria has allowed the determination of the species with large availability. Hydrodistillation from the fresh aerial parts of the three Algerian samples yields respectively (w/w) $0.05 \%, 0.04 \%$ and $0.03 \%$ of essential oils. GC-FID and GC/MS analyses of the three samples and subsequent fractions obtained by column chromatography allowed the identification of 24 components, accounting for more than $95 \%$ of the total composition (Table 2). The essential oil contains mostly linear oxygenated compounds, dominated by falcarinol (86.9-93.1\%), followed by octanal (1.0-1.8\%) and nonanal (0.2-0.4\%). Twenty-two components were identified by comparison of their retention indices and mass spectra with those in an in-house mass spectral library.

\section{Toxic activity of essential oil from Eryngium triquetrum against adult $B$. glabrata snails}

We independently assessed trial toxicity of three extractions of essential oil from E. triquetrum against adult B. glabrata, the vector snail of the trematode $S$. mansoni. At concentrations above $10 \mathrm{ppm}$, the mortality rate reached $100 \%$ whereby most of the exposed snails retracted into their shells with hemolymph expulsion. From concentrations of 0.5 to $1 \mathrm{ppm}$, the survival rate of exposed snails varied slightly between the three independent batches of oil extracted. Based on Probit analysis using the survival of treated snails to E. triquetrum oils, the concentration required to produce $50 \%$ mortality for deaths to $24 \mathrm{~h}$ after exposure $\left(\mathrm{LC}_{50}\right)$ was 0.51 , 0.63, 0.69 ppm for ET02, ET03 and ET01 respectively (Fig. 1). As the different $\mathrm{LC}_{50}$ values were relatively close, the following toxicity assays were performed with ET03 essential oil extract. Their $\mathrm{LC}_{90}$ values were 0.9 , 1.07 and 1.08 respectively. 


\section{Toxic activity of Eryngium triquetrum extract against infected snails}

The molluscicidal activity of the essential oil from E. triquetrum was also tested against snails infected with $S$. mansoni. Different essential oil concentrations around the $\mathrm{LC}_{50}$ were used under the same conditions as those described previously. Interestingly, this plant-derived molluscicide seems to be more potent against infected snails. Indeed, no toxic effects were observed in noninfected snails for a concentration of $0.1 \mathrm{ppm}$ while about $20 \%$ of infected snails were killed after $24 \mathrm{~h}$ exposure. At $0.5 \mathrm{ppm}$, the essential oil of E. triquetrum was 2 times more toxic to parasitized snails with a mortality rate of $88.8 \pm 4.8 \%$ whereas it was $38.9 \pm 12 \%$ in the noninfected snails (Fig. 2).

\section{Embryotoxicity evaluation on snail eggs}

Eryngium triquetrum extract was toxic to adult snails (infected or uninfected) in a dose-dependent manner (Figs. 1, 2). For the same range of concentrations, it appears that the egg masses are less sensitive to the essential oil extract. No difference of toxicity and lethality was observed in eggs exposed to concentrations below and around the $\mathrm{LC}_{50}$. The positive hatching rates were $91.3 \pm 4.7 \%, 93.3 \pm 2.8 \%$ at the concentrations of 0.1 and $0.5 \mathrm{ppm}$, respectively compared to the control which yielded $95.7 \pm 0.3 \%$ hatching. Embryos and adult B. glabrata snails showed different sensitivity to the plant extract since the lethal dose for $100 \%$ of the adult snail population (1 ppm) showed moderate embryonic lethal effect, $64.7 \pm 7.5 \%$ of snail embryos hatched and developed successfully (Fig. 3).

\section{Parasiticidal activity against the free-swimming larval stages of S. mansoni and effect on snail-parasite compatibility}

An alternative approach in control of schistosomiasis instead of controlling the snail population could be to focus on the free-swimming larval stages of the parasite, miracidia and cercariae. These parasite larval stages were exposed for 1 or $4 \mathrm{~h}$ to different concentrations of $E$. triquetrum extract ranging from 0.1 to $1 \mathrm{ppm}$ to evaluate its potential lethal effect. The mortality of the miracidia and cercariae of $S$. mansoni was nearly complete for 5, 1 and $0.5 \mathrm{ppm}$ of oil extract irrespective of the exposure time. For a concentration of $0.1 \mathrm{ppm}$, the mortality rate of miracidia dropped considerably reaching $7.6 \pm 2.7 \%$ and $29.3 \pm 8.0 \%$ with 1 and 4 hours of exposure (Fig. $4 a$ ). After a relatively short exposure time, severe surface damage on miracidia can be observed with a general loss of cilia that probably cause their immobility (Fig. 5). The mortality pattern for exposed cercariae was quite similar with $4.6 \pm 3.6 \%$ and $15.6 \pm 5.8 \%$ of deaths observed after the different contact times (Fig. 4b). To determine the ability of exposed miracidia to infect their host, sublethal concentrations of the essential oil from E. triquetrum were applied for $30 \mathrm{~min}$. Results of the snail exposure to treated $S$. mansoni miracidia are shown in Fig. 6. Miracidia exposed to low concentrations of plant extract were less infective with a prevalence of $3.3 \%$ compared to untreated miracidia (prevalence of $44 \%$ ).

\section{Discussion}

The eradication of schistosomiasis provided by the WHO's road map and planned for 2030 requires a significant investment from all disciplinary fields to develop new drugs against human schistosomes and to interrupt the parasite life-cycle. Even if the study of biological interactions between Schistosoma and its snail vector has taken a new dimension based on their genome sequencing studies [34, 35], the CRISPR production of parasite-resistant transgenic snails or genetically modified sterile worms are quite far from having any results because of technical difficulties and little-known ecological aspects of such releases [36, 37]. Currently, massive treatment with praziquantel and improving sanitation appear the best way to control the disease. However, new foci are appearing, and other are re-emerging probably due to global warming $[38,39]$ and mass human migration [40], but also to the emergence of drug-tolerant schistosomes [41, 42]. In this context, snail control appears to be a crucial strategy to ensure a sustainable control and elimination of schistosomiasis. A number of molluscicides have been developed in an attempt to decrease parasitic disease transmission. Among synthetic molluscicides, niclosamide is the most widely employed in official schistosomiasis control programmes [43, 44] although concerns about the emergence of resistant snail population remains [12] and its apparent toxicity to other living organisms has been observed [11, 45, 46]. In addition, it is often necessary to repeat spraying in treated transmission sites due to snail repopulation [44]. Consequently, increasing efforts focused on identifying and characterizing new plant-derived molluscicides is required as a safer alternative $[43,44]$. Among the molluscicidal agents extracted from plants, the latex from Euphorbia sp. appears promising by acting on both the snail vector and the parasite [13]. The $\mathrm{LC}_{50}$ can depend on several parameters such as Euphorbia species, the different part of the plant or the solvent used for latex extraction [47]. For example, $\mathrm{LC}_{50}$ of latex extracted from E. umbellata range from 1.36 to $40 \mathrm{ppm}[45,48]$ and around $30 \mathrm{ppm}$ and 0.5 from E. tirucalli and $E$. splendens, respectively $[49,50]$. Others plant extracts also display molluscicidal activities at concentrations 
Table 2 Percentage of different fractions of Eryngium triquetrum essential oil from three distinct geographical localities in Algeria

\begin{tabular}{|c|c|c|c|c|c|c|}
\hline \multirow[t]{2}{*}{ No } & \multirow[t]{2}{*}{ Components $^{\mathrm{a}}$} & \multirow[t]{2}{*}{$\mathrm{Rl}_{\mathrm{a}}^{\mathrm{b}}$} & \multicolumn{3}{|c|}{ Eryngium triquetrum } & \multirow[b]{2}{*}{ Identification } \\
\hline & & & ETO1 ${ }^{\mathrm{C}}$ & $\mathrm{ETO}^{\mathrm{C}}$ & ET03 & \\
\hline 1 & Heptane & 703 & 0.2 & 0.1 & 0.1 & $\mathrm{RI}, \mathrm{MS}$ \\
\hline 2 & Hexanal & 774 & 0.2 & 0.2 & 0.2 & $\mathrm{Rl}, \mathrm{MS}$ \\
\hline 3 & Heptanal & 877 & $\operatorname{tr}$ & $\operatorname{tr}$ & tr & $\mathrm{Rl}, \mathrm{MS}$ \\
\hline 4 & Octanal & 979 & 1.8 & 1.0 & 1.0 & $\mathrm{RI}, \mathrm{MS}$ \\
\hline 5 & (E)-2-octenal & 1039 & $\operatorname{tr}$ & $\operatorname{tr}$ & $\operatorname{tr}$ & $\mathrm{RI}, \mathrm{MS}$ \\
\hline 6 & 1-octanol & 1063 & 0.3 & 0.1 & 0.1 & $\mathrm{RI}, \mathrm{MS}$ \\
\hline 7 & Nonan-2-one & 1077 & $\operatorname{tr}$ & 0.1 & 0.1 & $\mathrm{RI}, \mathrm{MS}$ \\
\hline 8 & Nonanal & 1081 & 0.4 & 0.2 & 0.3 & $\mathrm{Rl}, \mathrm{MS}$ \\
\hline 9 & (E)-2-nonenal & 1133 & 0.4 & 0.3 & 0.2 & $\mathrm{RI}, \mathrm{MS}$ \\
\hline 10 & (Z)-2-nonen-1-ol & 1155 & 0.1 & 0.4 & 0.4 & $\mathrm{Rl}, \mathrm{MS}$ \\
\hline 11 & Octanoic acid & 1174 & 0.1 & $\operatorname{tr}$ & $\operatorname{tr}$ & $\mathrm{RI}, \mathrm{MS}$ \\
\hline 12 & 1-decen-3-ol & 1181 & 0.6 & tr & $\operatorname{tr}$ & $\mathrm{Rl}, \mathrm{MS}$ \\
\hline 13 & Decanal & 1183 & $\operatorname{tr}$ & 0.2 & 0.2 & $\mathrm{RI}, \mathrm{MS}$ \\
\hline 14 & 3-dodecen-1-yne & 1214 & 0.1 & $\operatorname{tr}$ & $\operatorname{tr}$ & $\mathrm{RI}, \mathrm{MS}$ \\
\hline 15 & Carvone & 1225 & $\operatorname{tr}$ & $\operatorname{tr}$ & $\operatorname{tr}$ & $\mathrm{Rl}, \mathrm{MS}$ \\
\hline 16 & (E)-2-decanal & 1251 & $\operatorname{tr}$ & 0.2 & 0.2 & $\mathrm{RI}, \mathrm{MS}$ \\
\hline 17 & $(\mathrm{E}, \mathrm{E})-2,4$-decadienal & 1289 & 0.3 & 0.3 & 0.3 & $\mathrm{Rl}, \mathrm{MS}$ \\
\hline 18 & $\beta$-ionone & 1454 & 0.2 & 0.2 & 0.2 & $\mathrm{RI}, \mathrm{MS}$ \\
\hline 19 & $\begin{array}{l}\text { 3,4-dimethyl-5-pentyl-5H- } \\
\text { furan-2-one }\end{array}$ & 1486 & 1.9 & 1.0 & 1.0 & RI, MS, Ref \\
\hline 20 & Y-undecalactone & 1524 & $\operatorname{tr}$ & $\operatorname{tr}$ & 0.2 & RI, MS, Ref \\
\hline 21 & Dodecanoic acid & 1547 & 0.1 & $\operatorname{tr}$ & $\operatorname{tr}$ & $\mathrm{Rl}, \mathrm{MS}$ \\
\hline 22 & Hexadecanoic acid & 1968 & 1.4 & 0.8 & 0.8 & $\mathrm{RI}, \mathrm{MS}$ \\
\hline 23 & falcarinol & 2026 & 86.9 & 93.1 & 90.6 & $\mathrm{Rl}, \mathrm{MS}$ \\
\hline 24 & a-kaurene & 2049 & 0.1 & 0.3 & 0.2 & $\mathrm{RI}, \mathrm{MS}$ \\
\hline Total identification (\%) & & & 95.1 & 98.3 & 96.2 & \\
\hline EO yields (\%) (w/w) & & & 0.05 & 0.04 & 0.03 & \\
\hline Oxygenated compounds & & & 92.8 & 95.4 & 92.7 & \\
\hline Hydrogenated compounds & & & 2.3 & 2.9 & 3.5 & \\
\hline
\end{tabular}

a Order of elution is given on apolar column (SPB-1)

b Retention indices on SPB-1 column $\left(\mathrm{RI}_{\mathrm{a}}\right)$

c Essential oils of E. triquetrum stems. Quantification was carried out using RFs relative to tridecane as internal standard

Abbreviations: \%, normalized percentages are given on the apolar column; tr, trace $(<0.05 \%)$; Rl: retention index; MS: mass spectrometry in electronic impact mode. All compounds were identified by comparing their El-MS and retention indices with references compiled in the in-house library except for compounds 19 and 20; EO: essential oil. Yield is based on the fresh weight of the stems; Ref, Compounds identified with references from literature data and compiled in the in-house library

lower that the one required by the WHO. Alcoholic stem extract from Jatropha gossypiifolia shows toxicity towards adult snails after $24 \mathrm{~h}$ exposure with a $\mathrm{LC}_{50}$ of $25 \mathrm{ppm}$ [51]. Chlorophyllin extracted from Moringa oleifera leaves has a lethal activity on adults Biomphalaria snails exposed during $24 \mathrm{~h}$ probably by interfering with nervous and digestive systems [52]. A Camellia oleifera extract enriched in saponin exhibits a high level of toxicity against adult $B$. alexandrina snails for which $\mathrm{LC}_{50}$ is quite similar to niclosamide, used as reference [14]. Other plant-derived terpenes such as jatrophone have also a high toxicity against adult snails
$[53,54]$. This list of plant-derived extracts with a potential molluscicidal activity is far from being exhaustive. Moreover, a recent review updates the different essential oils used for their toxic effect against schistosomiasis transmitting snails [55]. The most studied plants are those belonging to families Lamiacae, Rutaceae and Myrtaceae. The major chemical components determined by chromatography analyses are the terpenic derivatives for which their concentration in oils depend strongly on the nature of organic solvent and the different parts of plants used $[55,56]$. To our knowledge, the present study is the first to report the molluscicidal 


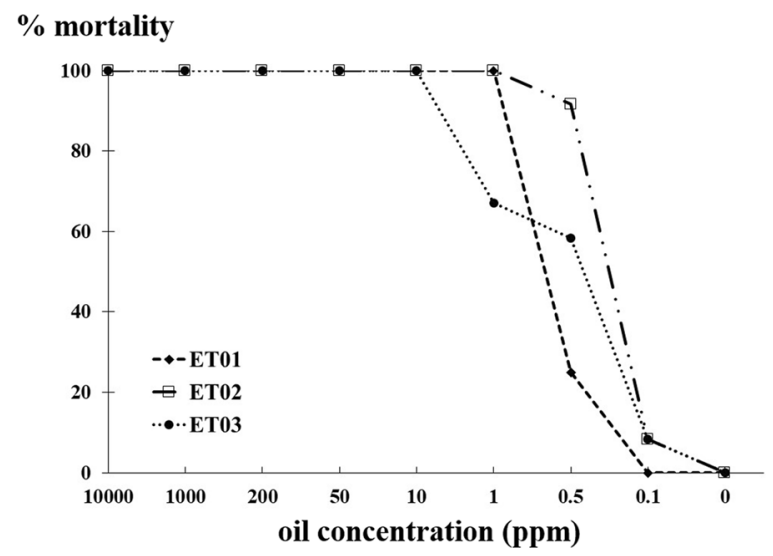

Fig. 1 Mortality rates of Biomphalaria glabrata at different concentrations of essential oil extracted from Eryngium triquetrum. Three independent fractions of essential oil extracts were tested and noted ET01, ET02 and ET03. Their respective compositions are reported in Table 2 Mortality rate was obtained by exposing 12 snails for each different concentrations of each essential oil

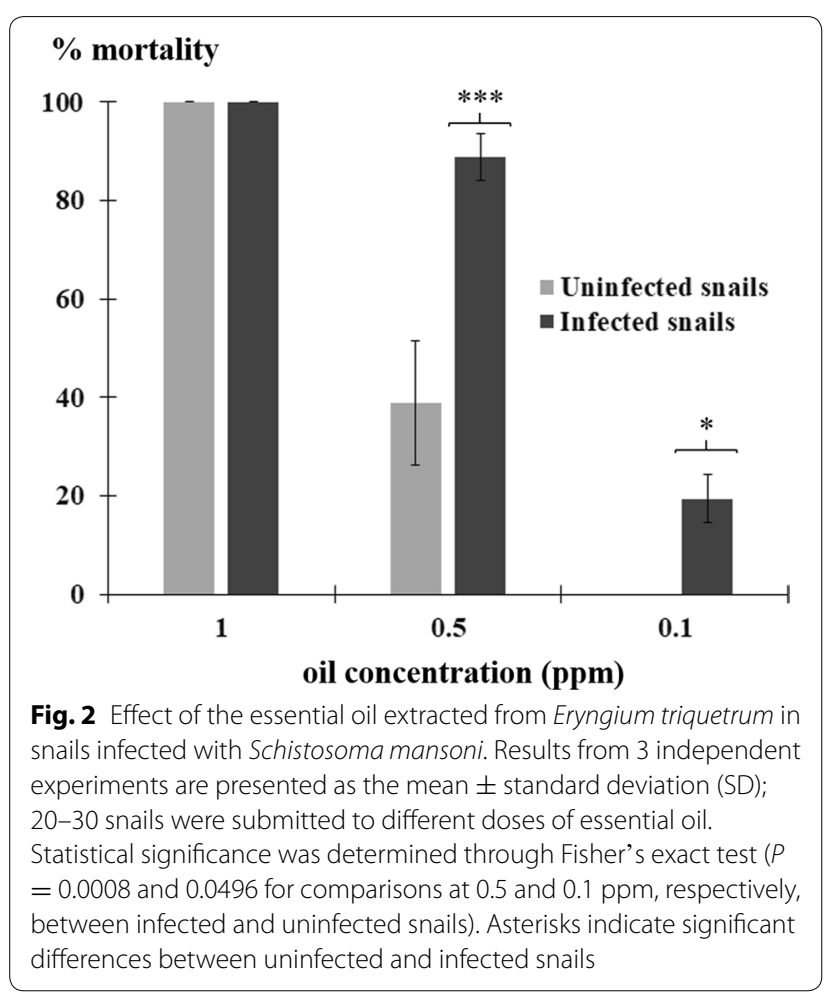

and parasiticidal activities of an essential oil extracted from an Apiaciae, Eryngium triquetrum. Its biological activities can be assigned to the high falcarinol content (about 90\%), an aliphatic polyacetylene molecule produced by several plants such as carrots [57]. Interestingly, the high level of this component is only found in

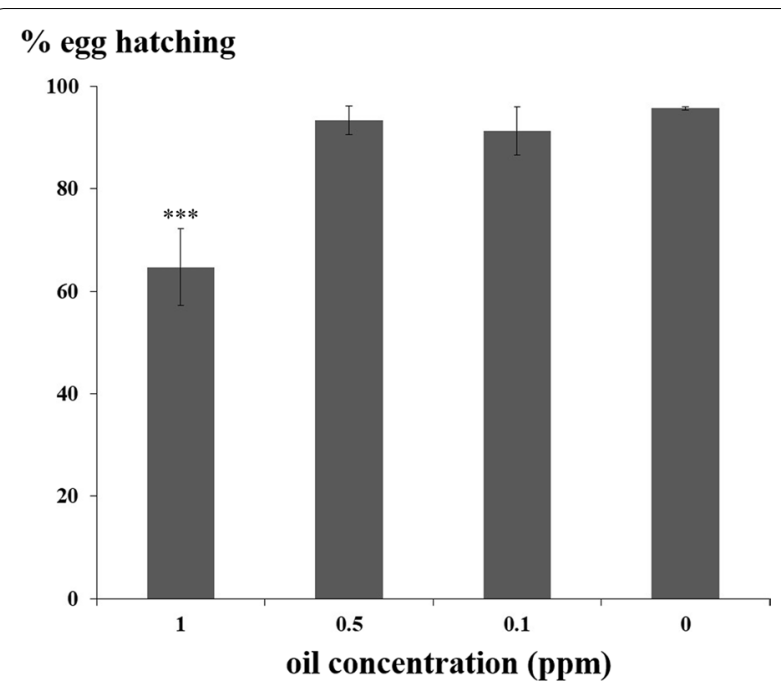

Fig. 3 Biomphalaria glabrata eggs and embryos exposed to essential oil from Eryngium triquetrum. The data are presented as the mean \pm standard deviation (SD). After $24 \mathrm{~h}$ of exposure to different concentrations of essential oil, egg hatching and snail development was monitored during 20 days. The term egg hatching corresponds here to a hatching leading to a normal development of the snail. This toxicity test was carried out twice on more than 25 egg masses per condition. Statistical significance was determined through Fisher exact test $(P<0.001)$. Asterisks indicate a significant difference between treated and non-treated eggs

E. triquetrum and could be considered as a main source of production. Indeed, essential oils of Eryngium species such as E. campestre, E. maritimum or E. alpinum do not contain such falcarinol compound or at lower concentrations [58-60]. As for E. planum, the maximal rate of falcarinol (about 60\%) is concentrated in roots which make it difficult to benefit from its biological activity [61]. As E. triquetrum from Algeria is a falcarinol-rich essential oil, especially from stems, exploitation at large farming scale could be proposed for molluscicidal but also therapeutic application. Indeed, falcarinol and/or essential oil from E. triquetrum display antimicrobial effect as well as anti-inflammatory properties [23, 59]. Also, falcarinol could be used in tumor treatment since cytotoxic activity against human cancer cell lines has been demonstrated [59, 62].

In the present study, the essential oil from E. triquetrum seems to be a promising molluscicidal candidate considering the standard criteria established by the WHO with a lethal concentration of $90 \%$ and $50 \%$ below 400 and 100 ppm respectively. The $\mathrm{LC}_{90}$ and $\mathrm{LC}_{50}$ values against adult B. glabrata snails of 1.02 and $0.61 \mathrm{ppm}$, respectively, are significantly lower than most of the well-characterized essential oils and similar to latex or niclosamide. Unlike the reference molluscicide, the lower toxicity of the essential oil from E. triquetrum to embryonated 
a

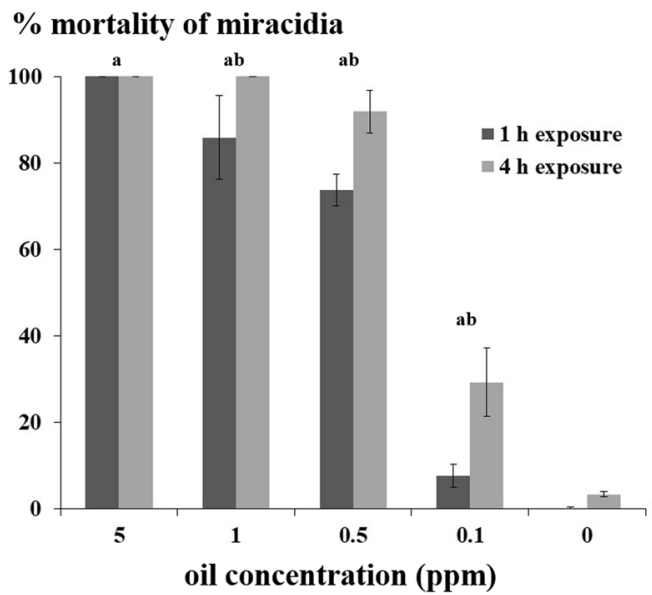

b

$\%$ mortality of cercariae

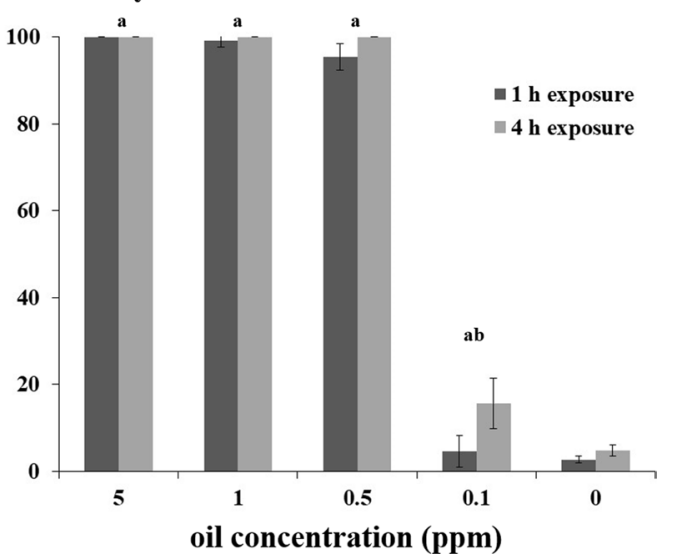

Fig. 4 Mortality of free-swimming larvae of Schistosoma mansoni exposed to essential oil from Eryngium triquetrum. Results are presented as the mean \pm standard deviation (SD) for at least 3 and 2 independent replicates for toxicity assays against miracidia and cercariae, respectively. About 300 miracidia and 100 cercariae were used for each independent experiment. The parasites (miracidia (a) and cercariae (b)) are considered dead if not mobile or motionless at the bottom of plates. Statistical significance was determined through Fisher exact test; "a" indicates a significant difference between the treated sample and the control, "b" indicates a significant difference between 1-h treated and 4-h treated parasites
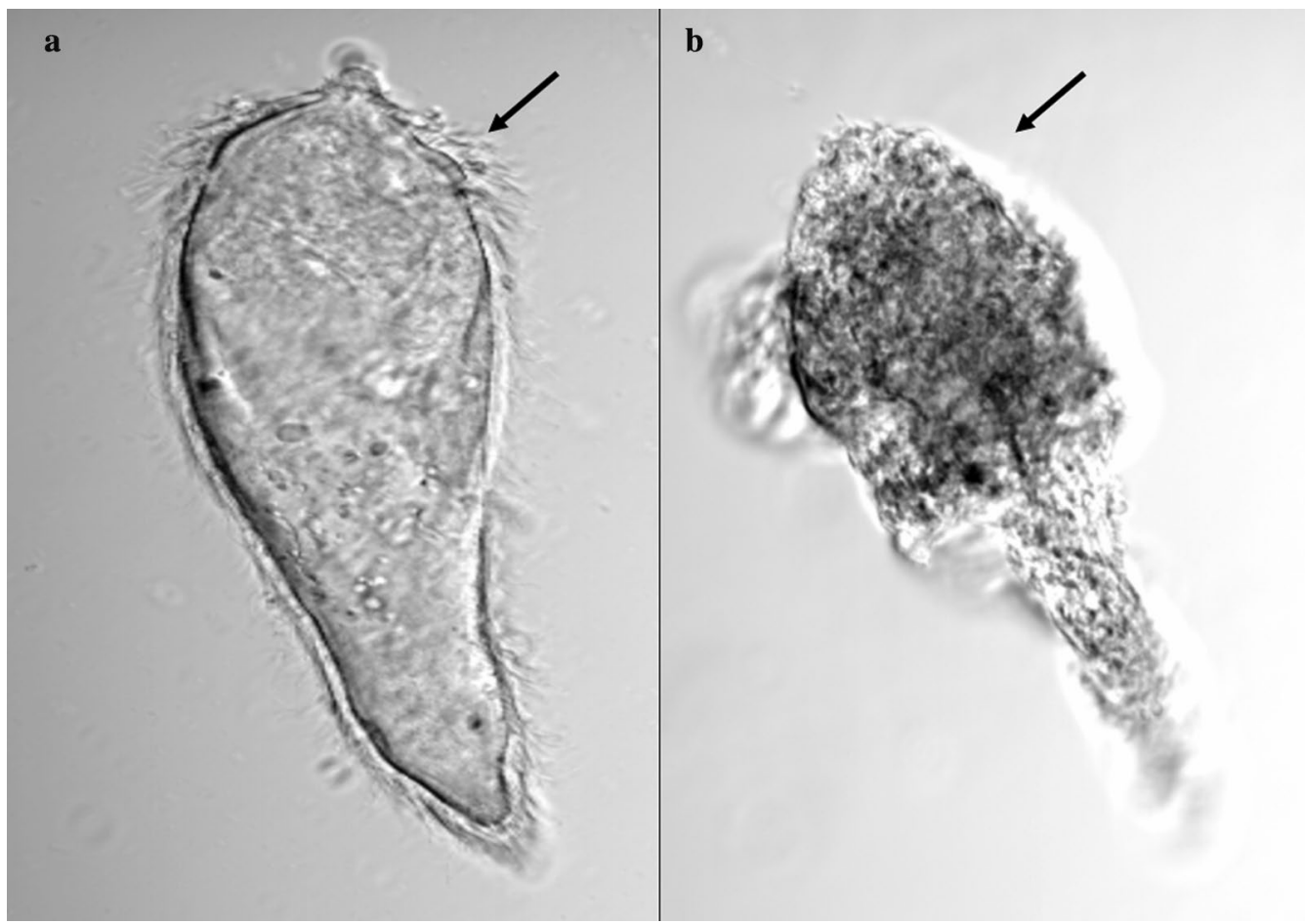

Fig. 5 Observation of parasiticidal activity on miracidia. a Miracidium not exposed to E. triquetrum essential oil. b Miracidum exposed to 0.5 ppm during $1 \mathrm{~h}$. Note surface alterations on miracidium exposed to E. triquetrum extract with total loss of ciliated plates (arrows)

eggs potentially due to a low penetrating ability into egg masses, suggests a higher specificity of action towards adult snails. This toxic dichotomy can be useful to treat the aquatic environment while reducing the side effects on non-target animals. The disruption of parasite's lifecycle is more favored when snails are even early infected. 


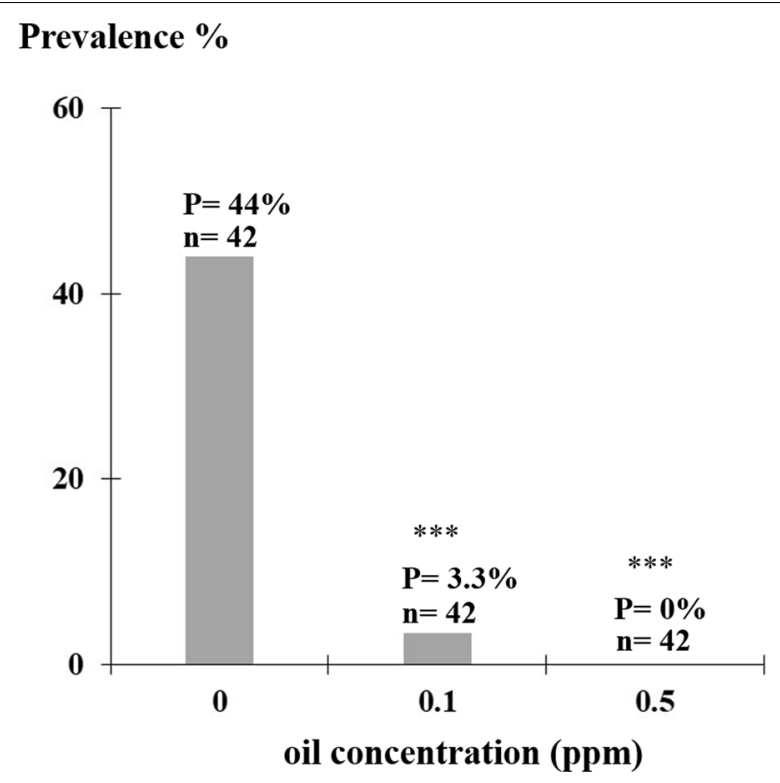

Fig. 6 Effect of Eryngium triquetrum extract on Schistosoma mansoni miracidia infectivity. Prevalence of snails exposed to miracidia treated with essential oil was assessed via cercarial shedding; 42 snails were individually exposed to one miracidium exposed to 0.1 or $0.5 \mathrm{ppm}$ of plant extract during a short exposure (30 min). All miracidia recovered were alive and swam toward light source. Data are presented as proportions of infected snails \pm standard error $(n=42)$. Statistical significance was determined through Fisher's exact test $(P<0.00001)$. Asterisks indicate a significant difference between treated and non-treated miracidia

This higher mortality in infected snails could be linked to a broad dysregulation of signaling pathways involved in detoxification [63] and/or energy production metabolism $[13,64]$.

In a context of schistosomiasis elimination goal, the characterization of biological activities from plantderived compounds mainly focuses on molluscicidal toxicity to break the parasite transmission cycle. However, some promising candidates present a dual activity by causing either the death of infective larvae $[16,17$, 65-67] or developmental abnormalities leading to a low pathogenicity [68]. Mortality values after being exposed only for $24 \mathrm{~h}$ at $0.5 \mathrm{ppm}$ were around $75 \%$ and $95 \%$ for miracidia and cercarciae, respectively, and close to $100 \%$ for both after $4 \mathrm{~h}$ exposure. Interestingly, no snail death was observed under the same experimental conditions (Additional file 1: Figure S1). This falcarinol-enriched extract from E. triquetrum also prevents parasite infestation. Indeed, at low level concentrations during a short time exposure (30 $\mathrm{min})$, the snail-parasite compatibility is strongly affected with no parasitized snails at $0.5 \mathrm{ppm}$. This significant loss of parasite virulence following treatment could be attributed to the shedding of the ciliated plates used by parasites for locomotion and penetration into the snail host (Fig. 5).

\section{Conclusions}

We present a complete analysis of biological activities of a falcarinol-enriched extract from an Apiaceae ranging from molluscicidal and parasiticidal activities to the infection capacity of the exposed parasites. The extract from E. triquetrum has shown promising results as an alternative molluscicidal and parasiticidal environmentally compatible agent to reduce snail infections with schistosomes in transmission foci. Future research could investigate the biological activity of synthetic or natural falcarinol and its derivatives to develop new agents to prevent schistosomiasis transmission.

\section{Supplementary information}

Supplementary information accompanies this paper at https://doi. org/10.1186/s13071-020-04367-w.

Additional file 1: Figure S1. Effect of short-time exposure to the essential oil extracted from Eryngium triquetrum on uninfected snails. Data are summarised as the mean and standard deviation (SD). Statistical significance was determined through Fisher's exact test. $P$-value $<0.05$ was considered statistically significant. A "a" indicates a significant difference between treated sample and control (Fischer's exact test; $P<0.001$ ); and " $\mathrm{b}$ " indicates a significant difference between $1 \mathrm{~h}$ treated and $4 \mathrm{~h}$ treated snails (Fisher's exact test; $P<0.001$ )

\section{Abbreviations}

ET: Eryngium triquetrum; LC: lethal concentration; MS: mass spectrometry; RI: retention index; $\mathrm{WHO}$ : world health organization.

\section{Acknowledgements}

The authors want to thank Cindy Louvet and Nathalie Arancibia for all aspects concerning the maintenance of the life-cycle of S. mansoni in B. glabrata. We thank all team members for their advice and helpful discussions. Also, the authors thank Josie Harris for revising the English writing of this paper. Paradev company is also warmly thanked for its technical support. The spectroscopic experiments have been performed using the Biodiversity and Biotechnologies Marines (Bio2Mar, http://bio2mar.obsbanyuls.fr/fr/index.html) facilities at the University of Perpignan via Domitia.

\section{Authors' contributions}

$N D, C B, R C A$ and DD designed the study. NM, AR, RCA and DD substantially participated in conception and improvement of research. NM and CB performed essential oil extraction and chemical characterization. RCA, AR, BG and DD performed all bioassays against snails and parasites. BG performed statistical analysis. RCA and DD carried out microscope observations. All authors contributed to the analysis and interpretation of the results. RCA, CB, ND and DD led the manuscript writing; all authors participated to manuscript writing, editing, and critical reviewing. All authors read and approved the final manuscript.

\section{Funding}

This study is set within the framework of the "Laboratoires d'Excellence (LABEX)"TULIP (ANR-10-LABX-41) and CeMEB (ANR-10-LABX-04-01).

\section{Availability of data and materials}

The datasets used during the present study are available from the corresponding author on reasonable request. 


\section{Ethics approval and consent to participate}

The laboratory and experimenters possessed an official certificate from the French Ministry of National Education, Research, and Technology, CNRS and DRAAF Languedoc Roussillon for experiments on animals, animal housing, and animal breeding (\# A66040; decree \# 87-848, October 19, 1987; and authorization \# 007083).

\section{Consent for publication}

Not applicable

\section{Competing interests}

The authors declare that they have no competing interests.

\section{Author details}

1 University Perpignan Via Domitia, IHPE, UMR 5244, CNRS, IFREMER, Perpignan, France. ${ }^{2}$ University Montpellier, IHPE, UMR 5244, CNRS, IFREMER, Montpellier, France. ${ }^{3}$ Faculté des Sciences, Département de Chimie, Université de Tlemcen, Laboratoire COSNA, Tlemcen, Algeria. ${ }^{4}$ EPHE-UPVD-CNRS, USR 3278 CRIOBE, Université de Perpignan, Perpignan, France. ${ }^{5}$ Laboratoire d'Excellence «CORAIL», Université de Perpignan, Perpignan, France. ${ }^{6}$ S.A.S. AkiNaO, Perpignan, France.

Received: 9 July 2020 Accepted: 17 September 2020

Published online: 23 September 2020

\section{References}

1. Batterman S, Eisenberg J, Hardin R, Kruk ME, Lemos MC, Michalak AM, et al. Sustainable control of water-related infectious diseases: a review and proposal for interdisciplinary health-based systems research. Environ Health Perspect. 2009;117:1023-32.

2. WHO W. Field use of molluscicides in schistosomiasis control programmes: an operational manual for programme managers. https:// www.who.int/schistosomiasis/resources/9789241511995/en. Accessed 3 Jul 2018.

3. Savioli L, Stansfield S, Bundy DA, Mitchell A, Bhatia R, Engels D, et al. Schistosomiasis and soil-transmitted helminth infections: forging control efforts. Trans R Soc Trop Med Hyg. 2002;96:577-9.

4. Savioli L, Albonico M, Engels D, Montresor A. Progress in the prevention and control of schistosomiasis and soil-transmitted helminthiasis. Parasitol Int. 2004;53:103-13.

5. Augusto RC, Duval D, Grunau C. Effects of the environment on developmental plasticity and infection success of Schistosoma parasites - an epigenetic perspective. Front Microbiol. 2019;10:1475.

6. Shiff C. Why reinvent the wheel? Lessons in schistosomiasis control from the past. PLoS Negl Trop Dis. 2017;11:e0005812.

7. Parker M, Allen T. Does mass drug administration for the integrated treatment of neglected tropical diseases really work? Assessing evidence for the control of schistosomiasis and soil-transmitted helminths in Uganda. Health Res Policy Syst. 2011;9:3.

8. Lamberton PHL, Faust CL, Webster JP. Praziquantel decreases fecundity in Schistosoma mansoni adult worms that survive treatment: evidence from a laboratory life-history trade-offs selection study. Infect Dis Poverty. 2017;6:110.

9. He P, Wang W, Sanogo B, Zeng X, Sun X, Lv Z, et al. Molluscicidal activity and mechanism of toxicity of a novel salicylanilide ester derivative against Biomphalaria species. Parasit Vectors. 2017;10:383.

10. Sures B, Nachev M, Selbach C, Marcogliese DJ. Parasite responses to pollution: what we know and where we go in 'Environmental Parasitology'. Parasit Vectors. 2017;10:65.

11. Oliveira-Filho EC, Paumgartten FJ. Toxicity of Euphorbia milii latex and niclosamide to snails and nontarget aquatic species. Ecotoxicol Environ Saf. 2000:46:342-50.

12. Dai JR, Li YZ, Wang W, Xing YT, Qu GL, Liang YS. Resistance to niclosamide in Oncomelania hupensis, the intermediate host of Schistosoma japonicum: should we be worried? Parasitology. 2015;142:332-40.

13. de Carvalho Augusto R, Mello Silva CC. Phytochemical molluscicides and schistosomiasis: what we know and what we still need to learn. Vet Sci. 2018:5:94.
14. Jia TW, Wang W, Sun LP, Lv S, Yang K, Zhang NM, et al. Molluscicidal effectiveness of Luo-Wei, a novel plant-derived molluscicide, against Oncomelania hupensis, Biomphalaria alexandrina and Bulinus truncatus. Infect Dis Poverty. 2019;8:27

15. Li H, Wang W. Apropos: critical analysis of molluscicide application in schistosomiasis control programs in Brazil. Infect Dis Poverty. 2017;6:54.

16. Matos JL, da Silva KR, de Lima Paula LA, Cunha WR, Ramos SB, Rodrigues $V$, et al. Molluscicidal and cercaricidal activities of curcumin on Biomphalaria glabrata and Schistosoma mansoni cercariae Molluscicidal and cercaricidal activities of curcumin. Pest Manag Sci. 2020;76:1228-34.

17. Silva H, Sa JLF, Siqueira WN, Lima MV, Martins MCB, Aires AL, et al. Toxicological effects of Ramalina aspera (lichen) on Biomphalaria glabrata snails and Schistosoma mansoni cercariae. Acta Trop. 2019;196:172-9.

18. Ibrahim AM, Ghoname SI. Molluscicidal impacts of Anagallis arvensis aqueous extract on biological, hormonal, histological and molecular aspects of Biomphalaria alexandrina snails. Exp Parasitol. 2018;192:36-41.

19. Mandefro B, Mereta ST, Tariku Y, Ambelu A. Molluscicidal effect of Achyranthes aspera L. (Amaranthaceae) aqueous extract on adult snails of Biomphalaria pfeifferi and Lymnaea natalensis. Infect Dis Poverty. 2017;6:133.

20. Bouzergoune F, Ciavatta ML, Bitam F, Carbone M, Aberkane MC, Gavagnin M. Phytochemical study of Eryngium triquetrum: isolation of polyacetylenes and lignans. Planta Med. 2016;82:1438-45.

21. Nusair SD, Ahmad MI. Toxicity of Vipera palaestinae venom and antagonistic effects of methanolic leaf extract of Eryngium creticum lam. Toxicon. 2019;166:1-8.

22. Paun G, Neagu E, Moroeanu V, Albu C, Savin S, Lucian Radu G. Chemical and bioactivity evaluation of Eryngium planum and Cnicus benedictus polyphenolic-rich extracts. Biomed Res Int. 2019;2019:3692605.

23. Medbouhi A, Merad N, Khadir A, Bendahou M, Djabou N, Costa J, et al. Chemical composition and biological investigations of Eryngium triquetrum essential oil from Algeria. Chem Biodivers. 2018;15:e1700343.

24. Medbouhi A, Tintaru A, Beaufay C, Naubron JV, Djabou N, Costa J, et al. Structural elucidation and cytotoxicity of a new 17-membered ring lactone from Algerian Eryngium campestre. Molecules. 2018;23:3250.

25. Sadiq A, Ahmad S, Ali R, Ahmad F, Zeb A, Ayaz M, et al. Antibacterial and antifungal potentials of the solvents extracts from Eryngium caeruleum, Notholirion thomsonianum and Allium consanguineum. BMC Complement Altern Med. 2016;16:478.

26. Europe Co. European Pharmacopoeia. 3rd ed. Strasbourg, France: Council of Europe; 1997.

27. Adams RP. Identification of essential oil components by gas chromatography/mass spectrometry. 4th ed. Carol Stream: Allured Publishing Corporation; 2007.

28. NIST. PC Version 1.7 of the NIST/EPA/NIH Mass Spectral Library. Gaithersburg, MD, USA: National Institute of Standards and Technology (NIST); 1999

29. Rubiolo P, Liberto E, Sgorbini B, Russo R, Veuthey JL, Bicchi C. Fast-GCconventional quadrupole mass spectrometry in essential oil analysis. J Sep Sci. 2008;31:1074-84

30. Djabou N, Paolini J, Desjobert J-M, Allali H, Baldovini N, Costa J, et al. Qualitative and quantitative analysis of volatile components of Teucrium massiliense L._-identification of 6-methyl-3-heptyl acetate as a new natural product. Flavour Fragrance J. 2010;25:475-87.

31. WHO. Guidelines for laboratory and field testing of molluscicides for control of schistosomiasis. Geneva: World Health Organization; 2019.

32. Mone Y, Mitta G, Duval D, Gourbal B. Effect of amphotericin B on the infection success of Schistosoma mansoni in Biomphalaria glabrata. Exp Parasitol. 2010;125:70-5.

33. Finney DJ. Probit analysis. 3rd ed. Cambridge: Cambridge University Press; 1971

34. Zerlotini A, Aguiar ER, Yu F, Xu H, Li Y, Young ND, et al. SchistoDB: an updated genome resource for the three key schistosomes of humans. Nucleic Acids Res. 2013:41:D728-31.

35. Adema CM, Hillier LW, Jones CS, Loker ES, Knight M, Minx P, et al. Whole genome analysis of a schistosomiasis-transmitting freshwater snail. Nat Commun. 2017;8:15451.

36. Famakinde DO. Treading the path towards genetic control of snail resistance to schistosome infection. Trop Med Infect Dis. 2018;3:86. 
37. Maier T, Wheeler NJ, Namigai EKO, Tycko J, Grewelle RE, Woldeamanuel Y, et al. Gene drives for schistosomiasis transmission control. PLoS Negl Trop Dis. 2019;13:e0007833.

38. Adekiya TA, Aruleba RT, Oyinloye BE, Okosun KO, Kappo AP. The effect of climate change and the snail-schistosome cycle in transmission and biocontrol of schistosomiasis in sub-Saharan Africa. Int J Environ Res Public Health. 2019;17:181.

39. Stensgaard AS, Vounatsou P, Sengupta ME, Utzinger J. Schistosomes, snails and climate change: current trends and future expectations. Acta Trop. 2019;190:257-68.

40. Le Govic Y, Kincaid-Smith J, Allienne JF, Rey O, de Gentile L, Boissier J. Schistosoma haematobium-Schistosoma mansoni hybrid parasite in migrant boy, France, 2017. Emerg Infect Dis. 2019;25:365-7.

41. Ismail M, Botros S, Metwally A, William S, Farghally A, Tao LF, et al. Resistance to praziquantel: direct evidence from Schistosoma mansoni isolated from Egyptian villagers. Am J Trop Med Hyg. 1999;60:932-5.

42. da Silva VBR, Campos B, de Oliveira JF, Decout JL, do Carmo Alves de Lima M. Medicinal chemistry of antischistosomal drugs: praziquantel and oxamniquine. Bioorg Med Chem. 2017;25:3259-77.

43. Coelho P, Caldeira RL. Critical analysis of molluscicide application in schistosomiasis control programs in Brazil. Infect Dis Poverty. 2016;5:57.

44. King $\mathrm{CH}$, Sutherland $L$, Bertsch D. Systematic review and meta-analysis of the impact of chemical-based mollusciciding for control of Schistosoma mansoni and S. haematobium transmission. PLoS Negl Trop Dis. 2015;9:e0004290.

45. Harrison AD. The effects of Bayluscid on gastropod snails and other aquatic fauna in Rhodesia. Hydrobiologia. 1966;28:371-84.

46. Souza CP. Molluscicide control of snail vectors of schistosomiasis. Mem Inst Oswaldo Cruz. 1995;90:165-8.

47. dos Santos AF, de Azevedo DP, dos Santos Mata Rda C, de Mendonça DI, Sant'Ana AE. The lethality of Euphorbia conspicua to adults of Biomphalaria glabrata, cercaria of Schistosoma mansoni and larvae of Artemia salina. Bioresour Technol. 2007;98:135-9.

48. Pereira L, Dias CN, Miranda MV, Firmo W, Rosa CDS, Santos PF, et al. Molluscicidal effect of Euphorbia umbellata (Pax) Bruyns latex on Biomphalaria glabrata, Schistosoma mansoni host snail. Rev Inst Med Trop Sao Paulo. 2017;59:e85.

49. Jurberg P, Cabral Neto JB, Schall VT. Molluscicide activity of the "avelós" plant (Euphorbia tirucalli L.) on Biomphalaria glabrata, the mollusc vector of schistosomiasis. Mem Inst Oswaldo Cruz. 1985;80:423-7.

50. de Vasconcellos MC, de Amorim A. Molluscicidal action of the latex of Euphorbia splendens var. hislopii N.E.B. ("Christ's Crown") (Euphorbiaceae) against Lymnaea columella (Say, 1817) (Pulmonata: Lymnaeidae), intermediate host of Fasciola hepatica Linnaeus, 1758 (Trematode: Fasciolidae): 1- test in laboratory. Mem Inst Oswaldo Cruz. 2003;98:557-63.

51. Pereira Filho AA, Franca CR, Oliveira Dda S, Mendes RJ, Goncalves Jde R, Rosa IG. Evaluation of the molluscicidal potential of hydroalcoholic extracts of Jatropha gossypiifolia Linnaeus, 1753 on Biomphalaria glabrata (Say, 1818). Rev Inst Med Trop Sao Paulo. 2014;56:505-10.

52. Ibrahim AM, Abdalla AM. Impact of Moringa oleifera seed aqueous extract on some biological, biochemical, and histological aspects of Biomphalaria alexandrina snails. Environ Sci Pollut Res Int. 2017;24:28072-8.

53. dos Santos AF, Fonseca SA, Cesar FA, de Azevedo Albuquerque MC, Santana JV, Santana AE. A penta-substituted pyridine alkaloid from the rhizome of Jatropha elliptica (Pohl) Muell. Arg. is active against Schistosoma mansoni and Biomphalaria glabrata. Parasitol Res. 2014;113:1077-84.

54. Radwan MA, El-Zemity SR, Mohamed SA, Sherby SM. Potential of some monoterpenoids and their new $\mathrm{N}$-methyl carbamate derivatives against schistosomiasis snail vector, Biomphalaria alexandrina. Ecotoxicol Environ Saf. 2008;71:889-94.

55. Pereira L, Ribeiro ECG, Brito MCA, Silveira DPB, Araruna FOS, Araruna FB, et al. Essential oils as molluscicidal agents against schistosomiasis transmitting snails—a review. Acta Trop. 2020;209:105489.

56. Lahlou M, Berrada R, Hmamouchi M. Molluscicidal activity of thirty essential oils on Bulinus truncatus. Therapie. 2001;56:71-2.

57. Rai DK, Brunton NP, Koidis A, Rawson A, McLoughlin P, Griffiths WJ. Characterisation of polyacetylenes isolated from carrot (Daucus carota) extracts by negative ion tandem mass spectrometry. Rapid Commun Mass Spectrom. 2011;25:2231-9.
58. Medbouhi A, Benbelaid F, Djabou N, Beaufay C, Bendahou M, QuetinLeclercq J, et al. Essential oil of Algerian Eryngium campestre: chemical variability and evaluation of biological activities. Molecules. 2019;24:2575.

59. Landoulsi A, Hennebelle T, Bero J, Rivière C, Sahpaz S, Quetin-Leclercq J, et al. Antimicrobial and light-enhanced antimicrobial activities, cytotoxicity and chemical variability of all Tunisian Eryngium species. Chem Biodivers. 2020;17:e1900543.

60. Kikowska M, Kalemba D, Dlugaszewska J, Thiem B. Chemical composition of essential oils from rare and endangered species-Eryngium maritimum L. and E. alpinum L. Plants (Basel). 2020;9:417.

61. Thiem B, Kikowska M, Kurowska A, Kalemba D. Essential oil composition of the different parts and in vitro shoot culture of Eryngium planum L. Molecules. 2011;16:7115-24.

62. Kobaek-Larsen M, Baatrup G, KhataeiNotabi M, El-Houri RB, Pipó-Ollé E, Christensen Arnspang E, et al. Dietary polyacetylenic oxylipins falcarinol and falcarindiol prevent inflammation and colorectal neoplastic transformation: a mechanistic and dose-response study in a rat model. Nutrients. 2019;11:2223.

63. Zhang SM, Buddenborg SK, Adema CM, Sullivan JT, Loker ES. Altered gene expression in the Schistosome-transmitting snail Biomphalaria glabrata following exposure to niclosamide, the active ingredient in the widely used molluscicide Bayluscide. PLoS Negl Trop Dis. 2015;9:e0004131.

64. el-Ansary A, Sammour EM, Soliman MS, Gawish FA. In vivo, attenuation of schistosome cercarial development and disturbance of egg laying capacity in Biomphalaria alexandrina using sublethal concentrations of plant molluscicides. J Egypt Soc Parasitol. 2001;31:657-69.

65. Rodrigues KA, Dias CN, do Amaral FM, Moraes DF, Mouchrek Filho VE, Andrade EH, et al. Molluscicidal and larvicidal activities and essential oil composition of Cymbopogon winterianus. Pharm Biol. 2013;51:1293-7.

66. dos Santos AF, Fonseca SA, César FA, de Azevedo Albuquerque MC, Santana JV, Santana AE. A penta-substituted pyridine alkaloid from the rhizome of Jatropha elliptica (Pohl) Muell. Arg. is active against Schistosoma mansoni and Biomphalaria glabrata. Parasitol Res. 2014;113:1077-84.

67. Ibrahim AM, Abdel-Gawad MM, El-Nahas HA, Osman NS. Studies on the molluscicidal activity of Agave angustifolia and Pittosporum tobira on schistosomiasis transmitting snails. J Egypt Soc Parasitol. 2015;45:133-41.

68. Augusto RC, Tetreau G, Chan P, Walet-Balieu ML, Mello-Silva CC, Santos $C P$, et al. Double impact: natural molluscicide for schistosomiasis vector control also impedes development of Schistosoma mansoni cercariae into adult parasites. PLoS Negl Trop Dis. 2017;11:e0005789.

\section{Publisher's Note}

Springer Nature remains neutral with regard to jurisdictional claims in published maps and institutional affiliations.

Ready to submit your research? Choose BMC and benefit from:

- fast, convenient online submission

- thorough peer review by experienced researchers in your field

- rapid publication on acceptance

- support for research data, including large and complex data types

- gold Open Access which fosters wider collaboration and increased citations

- maximum visibility for your research: over $100 \mathrm{M}$ website views per year

At BMC, research is always in progress.

Learn more biomedcentral.com/submissions 